\title{
Deoxybenzoin-containing polysulfones and polysulfoxides:
}

\author{
synthesis and thermal properties

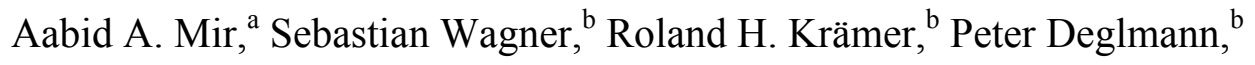 \\ Todd Emrick ${ }^{* a}$
}

${ }^{a}$ Polymer Science and Engineering Department, University of Massachusetts, 120 Governors Drive, Amherst, MA, 01003 USA.

${ }^{\mathrm{b}}$ BASF SE, 67056 Ludwigshafen, Carl-Bosch-Strasse 38, Germany.

*Corresponding authors. Tel.: +1 413 577-1613 (T. Emrick)

E-mail addresses: tsemrick@mail.pse.umass.edu

Keywords: Deoxybenzoin, polysulfone, heat release capacity.

\begin{abstract}
Novel poly(arylene ether) sulfones, sulfoxides, and sulfides containing deoxybenzoin subunits were synthesized by step growth polymerization involving bishydroxydeoxybenzoin (BHDB) and the corresponding sulfur-containing monomers. The isolated polymers demonstrated good solubility in organic solvents, making them easily processible into transparent, flexible, and creasable films upon solution casting. All of the polymers prepared exhibited exceptionally low flammability characteristics, with total heat release (THR) values as low as $6 \mathrm{~J} / \mathrm{g}-\mathrm{K}$, and char yield values as high as 54\%. Integration of deoxybenzoin monomers into polysulfones with 4,4'biphenyl led to heat release capacity (HRC) values less than half that of commercial polysulfones in use today, placing deoxybenzoin-based polysulfones and polysulfoxides into the ultra-low flammability category.
\end{abstract}

Introduction. Polymer flammability represents a pressing and persistent societal problem of growing importance with increasing global polymer production, consumption, and waste accumulation.[1] The abundance of synthetic polymers in construction, and transportation vehicles places safety concerns, such as flammability, at a high priority. Efforts to overcome the inherent flammability of high volume polymer materials, as well as specialty products, can improve the safety of polymers and reduce the frequency of fire-related catastrophic events.[2] 
Many large volume synthetic polymers are highly flammable, such as polyethylene, polystyrene, and poly(methyl methacrylate). Polymers with well-recognized intrinsically low flammability, such as Teflon and Kevlar, cannot nearly cover the range of materials applications for which polymer flammability is problematic. Thus, flame retardant additives, such as halogenated compounds and inorganic fillers, are employed in many finished polymer products. However, some additives carry drawbacks, ranging from toxicity to weakening of mechanical properties and diminished materials performance. New polymers are thus needed that, ideally, satisfy both materials performance and flammability requirements simultaneously, without the need for additives of any sort. At the same time, new non-halogenated polymeric additives that reduce the flammability of commodity polymers without sacrificing performance are also desirable. Each approach represents a significant challenge that, if met successfully, will contribute towards improved polymer materials safety.

Recent efforts to reduce the flammability of polymer materials range from new polymer syntheses, to additives and blends, to novel approaches in coating methodology. For example, Grunlan described environmentally friendly anti-flammable nanocoatings for textiles using coating techniques on foam that lead to pore blockage, while fibers coated with a clay-filled flame-retardant film retained their desired flexibility.[3] Morgan reported the synthesis and flammability evaluation of new boron- and phosphonate-containing aromatic flame retardant polymers produced by metal-catalyzed coupling, and found that adding boronic or phosphonic acids significantly lowered the heat release of the materials as a result of a condensed phase charring mechanism.[4-6] These polymers were blended with thermoplastic polyurethanes and evaluated by microscale combustion calorimetry (MCC) to afford low heat release polyurethane, with the boronic acids giving optimum performance. Wilkie showed that additives such as ammonium sulfamate, sodium diphenylamine-4-sulfonate, and 3-(1-pyridino)-1-propane sulfonate exhibited flame retardant effects on both polystyrene and poly(methyl methacrylate).[7] In another approach, reduction of polyurethane foam flammability was effected by carbon nanofiber (CNF) network formation, in which the network reduces dripping of melted material, and lowers HRR values.[8] Gilman described polymer nanocomposites based on nanoclay particles and the formation of a continuous protective solid carbonaceous layer following burning,[9-10] while Shen employed borates as flame retardants and smoke suppressants in both halogen-containing and halogen-free polymers.[11-13] Fire-resistant 
intumescent coatings protect a range of materials including wood, textiles and polymer composites, such as acrylic paints with inorganic flame retardant coating compositions.[14] In other approaches, nanoparticles and layer-by-layer (LbL) coatings were applied to the outer layers of thermosets for fire protection,[15-19] with the LbL approach on fabrics, foams, and thin films imparting dramatic improvements in anti-drip behaviour and char formation, while inhibiting flame spread.[20] The distinction of the approach we describe in this manuscript is seen in char-forming ability of deoxybenzoin-based structures, despite its hydrocarbon composition.

The selection of deoxybenzoin moieties for the preparation of low flammability polymers stems from their propensity to undergo substantive char formation upon burning, thus limiting the escape of flammable gas as a source of fuel.[21-23] The deoxybenzoin structure is set up for dehydration at high temperature -- under flash vacuum pyrolysis conditions diphenylacetylenes were noted to form from deoxybenzoin precursors.[24-26] Such a functional group transformation in the solid/melt state of a fire would produce polymeric phenylene ethynylenes that should quickly aromatize, cross-link, and char. With respect to characterizing polymer flammability, doing so on an experimental (milligram) scale is extremely useful for probing the potential suitability of novel polymers prior to scale-up efforts. For example, microscale combustion calorimetry (MCC), an oxygen consumption technique, identifies the heat release capacity (HRC) and total heat release (THR) of polymers, both key parameters for predicting polymer flammability in large scale tests, such as the widely implemented UL-94 test.[27-29] The bisphenol of deoxybenzoin, termed bishydroxydeoxybenzoin (BHDB), has now been integrated into several polymer compositions, including polyesters, polyurethanes and epoxy networks,[21,30-32] each giving materials with distinctly low HRC and THR values, while a BHDB-containing polyester was characterized as having a 5VA rating in the UL94 test, indicative of a very low flammability possessed by a material under these test conditions.

High performance polymers such as polyetherketone (PEK) and polyethersulfone are known for their thermal stability and flame resistant properties.[33-34] Nonetheless, with increasingly rigorous flammability standards,[35-37] we wanted to examine whether the properties of such polymers could be improved further by integrating deoxybenzoin moieties into these structures. This would require compatible polymerization chemistry of the deoxybenzoin monomers with 
the selected sulfur-containing monomers, such as nucleophilic displacement chemistry performed on the corresponding aromatic difluorides. Examples of polymers that proved amenable to inclusion of deoxybenzoin in the structure are described in this manuscript, as shown in Figure 1 for deoxybenzoin-containing sulfones 1, sulfoxides 2, and sulfone/sulfide copolymers 3 .

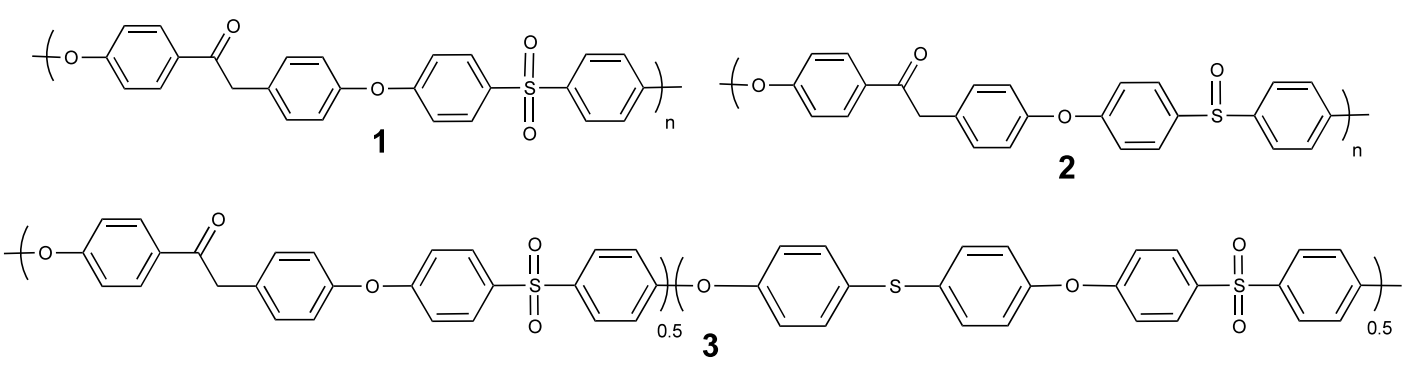

Figure 1. Chemical structures of deoxybenzoin-containing polymeric sulfones 1, sulfoxides 2, and sulfone/sulfide copolymers 3 .

\section{Experimental}

Materials. BHDB was prepared from desoxyanisoin[38] and purified by recrystallization from acetic acid. Desoxyanisoin, pyridine hydrochloride, bis(4-fluorophenyl)sulfone (99\%), potassium carbonate, 4,4'-thiodiphenol (99\%), thionyl chloride and aluminium chloride were purchased from Sigma-Aldrich. 4,4'-Biphenol (purity $>99.0 \%$ ) was purchased from TCI and used as received. Sulfolane and fluorobenzene were distilled under vacuum prior to use. Bis(4fluorophenyl)sulfoxide was synthesized as reported [42] and purified twice by recrystallization from hexane.

Characterization. Monomer syntheses were monitored by thin layer chromatography (TLC) and high performance liquid chromatography (HPLC) eluting with methanol and utilizing UVdetection at $254 \mathrm{~nm} .{ }^{1} \mathrm{H}$ and ${ }^{13} \mathrm{C}$ NMR spectra were recorded on a Bruker DPX300 spectrometer. Thermogravimetric analysis (TGA) was performed on a Q500 machine (TA Instruments) at a heating rate of $20^{\circ} \mathrm{C} / \mathrm{min}$ under $\mathrm{N}_{2(\mathrm{~g})}$ atmosphere (flow rate of $200 \mathrm{~mL} / \mathrm{min}$ ), and TGA values are reported as the temperature at which 5\% weight loss was observed $\left(\mathrm{T}_{\mathrm{d}}\right)$. Polymer glass transition temperature $\left(\mathrm{T}_{\mathrm{g}}\right)$ was determined by differential scanning calorimetry (DSC) on a Q200 machine (TA Instruments) with a heating rate of $10{ }^{\circ} \mathrm{C} / \mathrm{min}$ under $\mathrm{N}_{2(\mathrm{~g})}$ atmosphere. Specific heat release rate $(\mathrm{HRR}, \mathrm{W} / \mathrm{g})$, heat release capacity $(\mathrm{HRC}, \mathrm{J} /(\mathrm{g}-\mathrm{K}))$, and total heat release $(\mathrm{THR}, \mathrm{kJ} / \mathrm{g})$ were 
measured on a microscale combustion calorimeter (MCC). MCC was conducted over a temperature range of $80-750{ }^{\circ} \mathrm{C}$ at a heating rate of $1{ }^{\circ} \mathrm{C} / \mathrm{s}$ in an $80 \mathrm{~cm}^{3} / \mathrm{min}$ stream of nitrogen. The anaerobic thermal degradation products in the nitrogen gas stream mix with a $20 \mathrm{~cm}^{3} / \mathrm{min}$ stream of oxygen prior to entering the combustion furnace $\left(900^{\circ} \mathrm{C}\right)$. Heat release is quantified by standard oxygen consumption,[39-40] and HRR is obtained from $\mathrm{dQ} / \mathrm{dt}$ at each time interval and from the sample mass employed ( $5 \mathrm{mg}$ ). HRC is obtained by dividing the maximum HRR by the heating rate. Polymer molecular weight was measured by gel permeation chromatography (GPC) in $\mathrm{DMF}$ with $0.01 \mathrm{M} \mathrm{LiCl}$ at $50{ }^{\circ} \mathrm{C}$ and calibrated against poly(methyl methacrylate) (PMMA) standards. GPC was operated at an eluent flow rate of $1 \mathrm{~mL} / \mathrm{min}$ with a Sonntek K-501 pump, one $50 \times 7.5 \mathrm{~mm}$ PL gel mixed guard column, one $300 \times 7.5 \mathrm{~mm}$ PL gel $5 \mu \mathrm{m}$ mixed C column, one $300 \times 7.5 \mathrm{~mm}$ PL gel $5 \mu \mathrm{m}$ mixed D column, and using a Knauer refractive index detector (K-2301) and an Alltech model 3000 solvent recycler.

Synthesis of 4,4'-bishydroxydeoxybenzoin 4 (BHDB). BHDB was prepared according to a published procedure.[38] In short, desoxyanisoin (100 g, $390 \mathrm{mmol})$ and pyridine hydrochloride $(180 \mathrm{~g}, 1.56 \mathrm{~mol})$ were added to a round bottom flask equipped with a condenser and magnetic stir bar. The mixture was refluxed at $200{ }^{\circ} \mathrm{C}$ for $5 \mathrm{~h}$, cooled to room temperature, poured into cold water, filtered, and crystallized from acetic acid to afford BHDB as an off-white crystalline solid (76 g, 85\%), mp 210-212 ${ }^{\circ} \mathrm{C} .{ }^{1} \mathrm{H}$ NMR (DMSO-d $6,300 \mathrm{MHz}$ ): $\delta 10.35$ (s, 1H, OH- Ar-CO), $9.28\left(\mathrm{~s}, 1 \mathrm{H}, \mathrm{OH}-\mathrm{Ar}-\mathrm{CH}_{2}\right), 7.91(\mathrm{~d}, 2 \mathrm{H}), 8.7(\mathrm{Ar}-\mathrm{H}), 7.04(\mathrm{~d}, 2 \mathrm{H}), 8.5(\mathrm{Ar}-\mathrm{H}), 6.84(\mathrm{~d}, 2 \mathrm{H}), 8.7$ $(\mathrm{Ar}-\mathrm{H}), 6.68(\mathrm{~d}, 2 \mathrm{H}), 8.5(\mathrm{Ar}-\mathrm{H}), 4.11 \mathrm{ppm}(\mathrm{s}, 2 \mathrm{H}, \mathrm{Ar}-\mathrm{CO}-\mathrm{CH} 2-\mathrm{Ar}) .{ }^{13} \mathrm{C}$ NMR (DMSO-d 6 ): $\delta$ $196.5,162.3,156.2,131.3,130.7,128.1,125.9,115.5,115.4,43.7$ ppm.

Synthesis of polysulfone 1 . To a $100 \mathrm{~mL}$ three-necked, roundbottom flask equipped with a Dean Stark trap, condenser, magnetic stirrer, and nitrogen inlet was added BHDB (2.280 $\mathrm{g}, 10 \mathrm{mmol})$, bis(4-fluorophenyl)sulfone $(2.60 \mathrm{~g}, 10.2 \mathrm{mmol})$, anhydrous $\mathrm{K}_{2} \mathrm{CO}_{3}(1.40 \mathrm{~g}$, $10.2 \mathrm{mmol})$, sulfolane $(9.5 \mathrm{~g})$, and toluene $(10 \mathrm{~mL})$. The mixture was heated to remove water from toluene by azeotropic distillation. The resulting mixture was stirred at 160$180{ }^{\circ} \mathrm{C}$ for 2-3 $\mathrm{h}$. When the mixture became too viscous to allow stirring, an additional 2$3 \mathrm{~g}$ of sulfolane was added, and stirring was continued at $180^{\circ} \mathrm{C}$ for $30 \mathrm{~min}$. The mixture was cooled to room temperature and diluted with dichloromethane. This solution was poured into methanol $(300 \mathrm{~mL})$ containing acetic acid $(2 \mathrm{~mL})$, which resulted in 
precipitation. The precipitated polymer was collected by filtration and redissolved in dichloromethane, and the solution was filtered through a thin layer of Celite to remove inorganic salts. This solution was added to methanol for precipitation. Polymer 1 was collected by filtration and dried under vacuum at $80{ }^{\circ} \mathrm{C}$ for $24 \mathrm{~h}$ to afford a white fibrous material (4.20 g, 95\% yield). ${ }^{1} \mathrm{H}$ NMR $\left(\mathrm{CDCl}_{3}, 300 \mathrm{MHz}\right): \delta 4.29$ (s, 2H, Ar-CO-CH2Ar), 7.00-7.40 (m, 8H, Ar-H), 7.28-7.30 (d, 2H, Ar-H), 7.84-7.97 (m, 4H, Ar-H), 8.05 (d, 2H). ${ }^{13} \mathrm{C} \mathrm{NMR}\left(\mathrm{CDCl}_{3}\right)$ : 44.41, 115.56, 117.84, 119.34, 120.54, 130.09, 131.09, 132.629, $135.45,136.72,153.87,155.06,159.44,160.28,161.85,195.98$ ppm. FT-IR $\left(\mathrm{cm}^{-1}\right): 3078$, $1677,1579,1486,1408,1291,1234,1102,1009,993,871,832,685 . M_{n} 18400, M_{w}$ 57000, PDI 3.1

Synthesis of polysulfoxide 2. To a $25 \mathrm{~mL}$ three-necked, roundbottom flask equipped with a Dean Stark trap, condenser, magnetic stirrer, and $\mathrm{N}_{2(\mathrm{~g})}$ inlet was added BHDB (1.14 g, $5.00 \mathrm{mmol})$, bis(4-fluorophenyl)sulfoxide $(1.19 \mathrm{~g}, 5.00 \mathrm{mmol})$, anhydrous $\mathrm{K}_{2} \mathrm{CO}_{3}(0.71 \mathrm{~g}$, $5.2 \mathrm{mmol})$, sulfolane $(4.5 \mathrm{~g})$, and toluene $(5 \mathrm{~mL})$. The mixture was heated to remove water (from toluene) by azeotropic distillation. The resulting mixture was heated at 170$180^{\circ} \mathrm{C}$ for $15 \mathrm{~h}$. When the mixture became viscous it was cooled to room temperature and diluted with dichloromethane. This solution was poured into methanol $(200 \mathrm{~mL})$ containing acetic acid $(2 \mathrm{~mL})$, which resulted in precipitation. The precipitated polymer was collected by filtration and redissolved in dichloromethane, and the solution was filtered through a thin layer of Celite to remove inorganic salts. The polymer was purified further by precipitation into methanol. Polymer 2 was collected by filtration and dried under vacuum at $80{ }^{\circ} \mathrm{C}$ for $24 \mathrm{~h}$ to afford white fibrous polymer. $(1.72 \mathrm{~g}, 80.6 \%$ yield). ${ }^{1} \mathrm{H}$ NMR $\left(\mathrm{CDCl}_{3}, 300 \mathrm{MHz}\right.$ ): 4.27 (s, 2H, Ar-CO-CH2-Ar), 6.90-7.26 (m, 10H, Ar-H), 7.56-7.69 (m, 4H), 8.03-8.06 (d, 2H, Ar-H). ${ }^{13} \mathrm{C}$ NMR $\left(\mathrm{CDCl}_{3}\right)$ : 44.50, 116.85, $118.22,120.14,127.09,131.03,138.71,140.56,154.61,158.21,160.53,195.99$ ppm. FTIR $\left(\mathrm{cm}^{-1}\right): 3060,1675,1597,1504,1483,1087,1041,871,829 . M_{n} 13400, M_{w} 43500$, PDI 3.2 .

Representative synthesis of copolymer 9. To a $25 \mathrm{~mL}$ three-necked, roundbottom flask equipped with a Dean Stark trap, condenser, magnetic stirrer, and nitrogen inlet was added BHDB (0.570 g, $2.50 \mathrm{mmol})$, 4,4'-biphenol (0.465 g, $2.50 \mathrm{mmol})$, bis(4- 
fluorophenyl)sulfone $(1.270 \mathrm{~g}, 5.00 \mathrm{mmol})$, anhydrous $\mathrm{K}_{2} \mathrm{CO}_{3}(0.72 \mathrm{~g}, 5.2 \mathrm{mmol})$, sulfolane $(4.2 \mathrm{~g})$, and toluene $(5 \mathrm{~mL})$. The mixture was heated to remove water from toluene by azeotropic distillation and stirred at $160-180{ }^{\circ} \mathrm{C}$ for $3-4 \mathrm{~h}$. When the mixture became too viscous to stir, an additional $2 \mathrm{~g}$ of sulfolane was added, and stirring was continued at $180^{\circ} \mathrm{C}$ for $30 \mathrm{~min}$. The mixture was then cooled to room temperature and diluted with dichloromethane. This solution was poured into methanol (200 $\mathrm{mL})$ containing acetic acid $(2 \mathrm{~mL})$, which resulted in precipitation of the polymer. The precipitated polymer was collected by filtration and redissolved in dichloromethane. The dichloromethane solution was filtered through a thin layer of Celite to remove inorganic salts, and the polymer was purified further by precipitation into methanol. Polymer 9 was collected by filtration and dried under vacuum at $80^{\circ} \mathrm{C}$ for $24 \mathrm{~h}$ to afford white fibrous polymer (2.0 g, 95\% yield). ${ }^{1} \mathrm{H}$ NMR $\left(\mathrm{CDCl}_{3}, 300 \mathrm{MHz}\right): \delta 4.30$ (s, 2H, Ar-CO-CH $\left.2-\mathrm{Ar}\right)$, 7.12-7.29 (m, 19H), $7.60(\mathrm{~s}, 4 \mathrm{H}), 7.92-8.01(\mathrm{~m}, 10 \mathrm{H}) .{ }^{13} \mathrm{C} \mathrm{NMR}\left(\mathrm{CDCl}_{3}\right): \delta 44.52(\mathrm{CH} 2-$ CO), 117-120, 129-137, 153-154, 159-161, 196. FT-IR $\left(\mathrm{cm}^{-1}\right)$ : 3068, 1678, 1582, 1484 , 292, 1233, 1163, 1103, 1007, 830, 686. $\mathrm{M}_{\mathrm{n}}$ 34000, $\mathrm{M}_{\mathrm{w}}$ 64000, PDI 1.9.

Representative synthesis of copolymer 10. To a $25 \mathrm{~mL}$ three-neck round bottom flask equipped with a Dean Stark trap, condenser, magnetic stirrer, and $\mathrm{N}_{2(\mathrm{~g})}$ inlet was added BHDB (0.570 g, $2.5 \mathrm{mmol}), 4,4$ '-thiodiphenol (0.545 g, $2.50 \mathrm{mmol})$, bis(4fluorophenyl)sulfone $(1.271 \mathrm{~g}, 5.00 \mathrm{mmol})$, anhydrous $\mathrm{K}_{2} \mathrm{CO}_{3}(0.76 \mathrm{~g}, 5.5 \mathrm{mmol})$, sulfolane $(4.5 \mathrm{~g})$, and toluene $(5 \mathrm{~mL})$. The mixture was heated to remove water from toluene by azeotropic distillation, then heated at $160-180^{\circ} \mathrm{C}$ for $2-3 \mathrm{~h}$. When the mixture became too viscous to stir, an additional $2 \mathrm{~g}$ of sulfolane was added, and stirring was continued at $180^{\circ} \mathrm{C}$ for $30 \mathrm{~min}$. The mixture was then cooled to room temperature and diluted with dichloromethane. This solution was poured into methanol (200 $\mathrm{mL})$ containing acetic acid $(2 \mathrm{~mL})$, which resulted in precipitation. The precipitated polymer was collected by filtration and redissolved in dichloromethane, and this solution was filtered through a thin layer of Celite to remove inorganic salts. The polymer was purified further by precipitation into methanol, then collected by filtration and dried under vacuum at $80{ }^{\circ} \mathrm{C}$ for $24 \mathrm{~h}$ to afford a white fibrous material $(2.01 \mathrm{~g}, 92 \%$ yield $) .{ }^{1} \mathrm{H}$ NMR $\left(\mathrm{CDCl}_{3}, 400 \mathrm{MHz}\right): 4.33$ (s, 2H, Ar-CO-CH2-Ar), 7.01-7.13 (m, 16H, Ar-H), 7.28-7.31 (d, 
$2 \mathrm{H}, J=12)$, 7.36-7.38 (d, 4H, $J=8), 7.85-7.95(\mathrm{~m}, 8 \mathrm{H}, \mathrm{Ar}-\mathrm{H}), 8.06-8.08(\mathrm{~d}, 2 \mathrm{H}, J=8)$.

${ }^{13} \mathrm{C}$ NMR $\left(\mathrm{CDCl}_{3}\right): 45.50,119.30,120.66,121.97,131.33,132.84,134.45,136.58$, 155.38, 161.24, 163.50, 197.30 ppm. FT-IR $\left(\mathrm{cm}^{-1}\right): 3078,1678,1578,1481,1233,1175$, $1103,1009,829,691 . M_{n} 48,100 ; M_{w} 128,000 ;$ PDI 2.6 .

\section{Results and discussion}

4,4'-Bishydroxydeoxybenzoin (BHDB), prepared readily by demethylation of desoxyanisoin in neat pyridine hydrochloride,[38] was utilized in step growth polymerization with sulfur-containing aromatic monomers as described below. Scheme 1 shows the polymerization of BHDB with the selected sulfur-containing aromatic difluorides, accomplished by nucleophilic aromatic substitution in aprotic solvents using potassium carbonate as base and sulfolane as a stable, high boiling solvent.

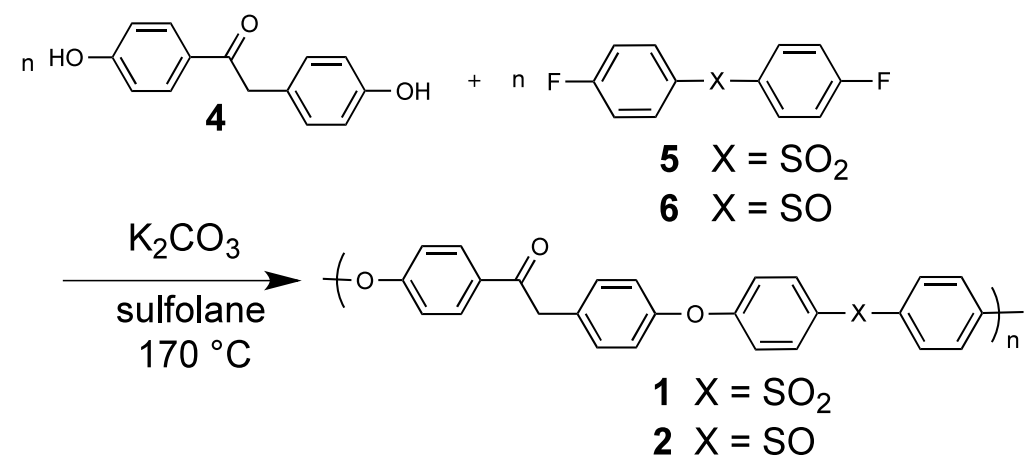

Scheme 1. Polycondensation of BHDB with difluoroaromatic sulfone and sulfoxide monomers 5 and 6.

Polysulfone 1 was synthesized by polycondensation of BHDB and bis(4-fluorophenyl)sulfone in sulfolane to afford polymer products with relatively high molecular weight $\left(\mathrm{M}_{\mathrm{n}}\right.$ approaching 50 $\mathrm{kDa})$ relative to PMMA standards. These solution polymerizations were conducted at 170$180{ }^{\circ} \mathrm{C}$ for 2-3 $\mathrm{h}$ using magnetic stirring under a $\mathrm{N}_{2(\mathrm{~g})}$ atmosphere. While other polar aprotic solvents, such as dimethylsulfoxide (DMSO) or N-methylpyrrolidone (NMP) could be used, sulfolane was preferred for the high reaction temperatures it allows, and toluene $(10 \mathrm{~mL})$ was added to the reaction mixture to afford an anhydrous system by its azeotropic distillation with water. The polymerization mixture was heated to $140-150{ }^{\circ} \mathrm{C}$ while stirring for $2 \mathrm{~h}$, then to 
$180{ }^{\circ} \mathrm{C}$ under constant purging with $\mathrm{N}_{2(\mathrm{~g})}$. The mixture was cooled to room temperature, diluted with dichloromethane, and precipitated into methanol/acetic acid. The precipitated polymer was collected by filtration, redissolved in dichloromethane, and filtered through Celite to remove inorganic salts. The polymer was purified further by precipitation into methanol, then isolated by filtration as a white fibrous material. ${ }^{1} \mathrm{H}$ NMR spectroscopy of polysulfone $\mathbf{1}$ in $\mathrm{CDCl}_{3}$ showed a signal for the methylene protons of BHDB at $4.30 \mathrm{ppm}$, while ${ }^{13} \mathrm{C}$ NMR revealed the carbonyl carbon resonance of the deoxybenzoin moiety at $196 \mathrm{ppm}$, a signal at $44.5 \mathrm{ppm}$ for the methylene carbon, and aromatic resonances from 115-162 ppm. Aromatic polysulfoxides 2 were synthesized similarly, using bis(4-fluorophenyl)sulfoxide as the sulfoxide monomer, which was synthesized by Friedel-Crafts acylation of fluorobenzene with thionyl chloride.[42]

The polymerization of BHDB with bis(4-fluorophenyl)sulfone was conducted over $2 \mathrm{hrs}$ to afford polysulfone 1 of molecular weight Mn 18,400 and Mw 57,000 ( $\mathrm{Mn}=$ number-average molecular weight; $\mathrm{Mw}=$ weight-average molecular weight). Under similar conditions, BHDB polymerization with sulfoxide $\mathbf{6}$ affording polysulfoxide $\mathbf{2}$ proceeded more slowly, requiring 15 hours to afford polymer samples of Mn 13,400 and Mw 43,500. The faster polymerization in the sulfone case is attributed to its greater electron withdrawing capacity and C-F bond activation.[41-42] The temporal evolution of molecular weight was monitored by gel permeation chromatography (GPC) against PMMA calibration standards, performed on aliquots taken at several time intervals during the course of the polymerization (shown in Figure 2 for polysulfoxide 2 ).

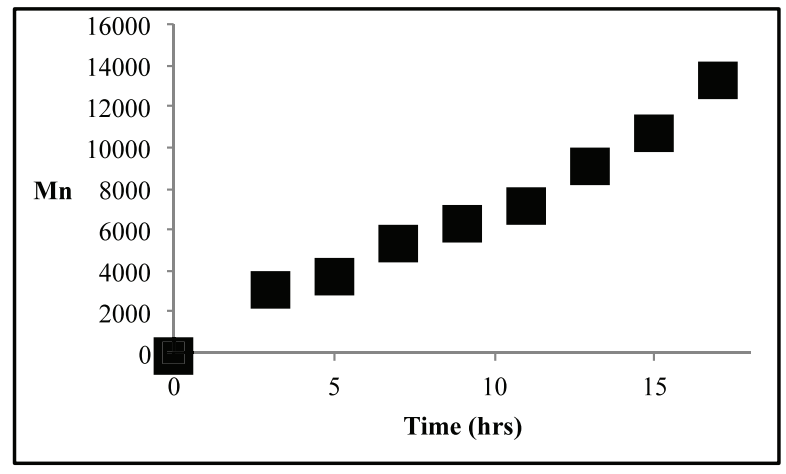

Figure 2. Plot of number-average molecular weight as a function of time (hrs) for polysulfoxide 2.

Copolymerization of BHDB with bis(4-fluorophenyl)sulfone and 4,4'-biphenol or 4,4'thiodiphenol (Scheme 2) was performed in sulfolane in the presence of potassium carbonate to afford the desired polymers $\mathbf{9}$ and $\mathbf{1 0 .}$ 


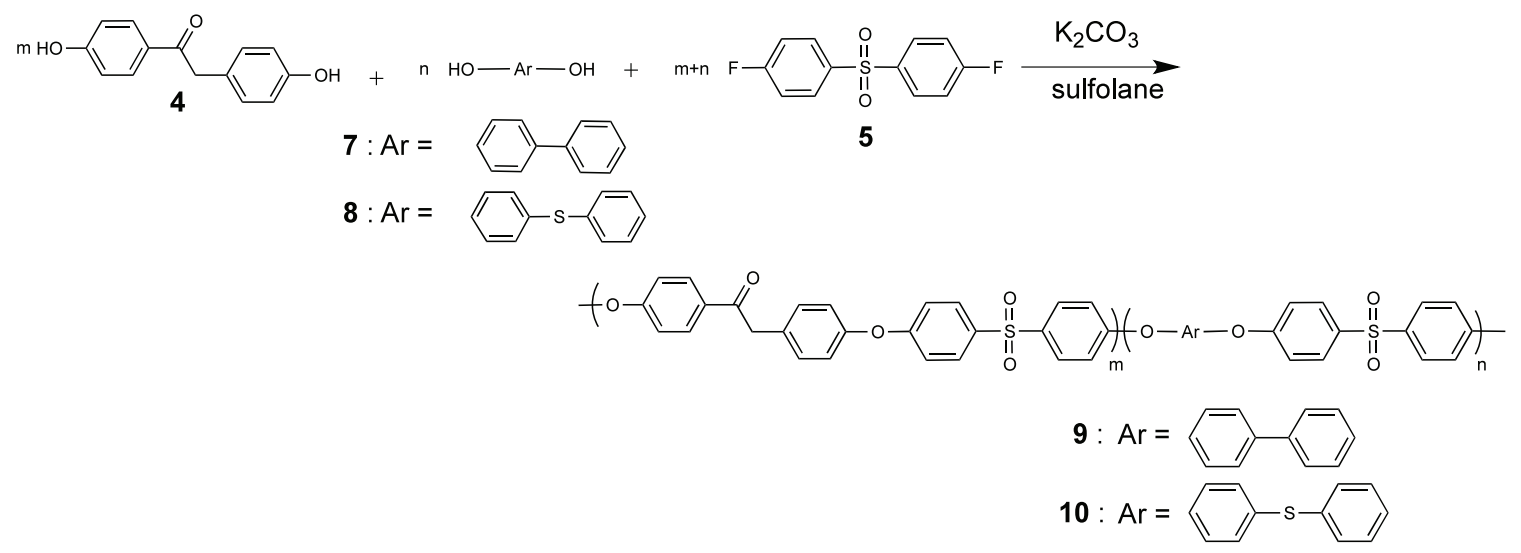

Scheme 2. Copolymerization of BHDB with aromatic monomers 5,7 and $\mathbf{8}$.

The polymer products were soluble in common organic solvents, and casting from $\sim 2-5 \mathrm{mg} / \mathrm{mL}$ dichloromethane solution produced transparent flexible films, such as seen for polysulfone $\mathbf{1 0}$ in Figure 3.

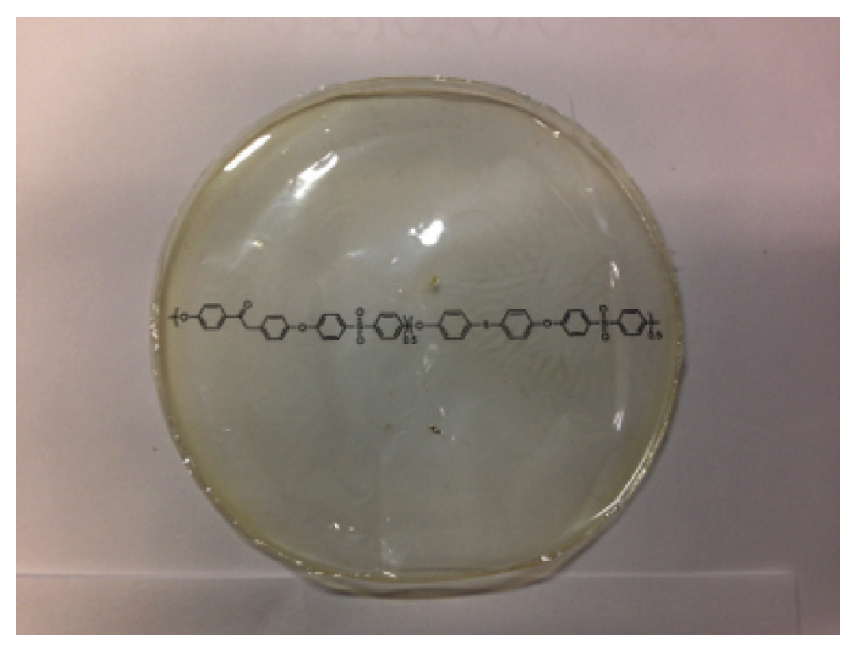

Figure 3. Solution cast film of deoxybenzoin-containing polysulfone $\mathbf{1 0 .}$

These films exhibited excellent properties, judged qualitatively, with apparent transparency and amenability to manual folding and creasing without inducing damage. The relative ratio of the two bisphenols (4,4'-thiodiphenol and BHDB) incorporated into polysulfone $\mathbf{1 0}$ was calculated by integration of the solution ${ }^{1} \mathrm{H}$ NMR spectra. For example, the singlet at $\delta 4.33 \mathrm{ppm}$ representing the two methylene protons of the deoxybenzoin was integrated against the resonance at $\delta 7.36 \mathrm{ppm}$ for the four aromatic protons adjacent to the sulfur of 4,4'-thiodiphenol. 
${ }^{13} \mathrm{C}-\mathrm{NMR}$ spectroscopy showed signals at 197.3 and $45.5 \mathrm{ppm}$, representing the deoxybenzoin carbonyl and methylene groups, respectively. Infrared spectroscopy confirmed the expected carbonyl content in the copolymer, with characteristic stretching at $1678 \mathrm{~cm}^{-1}$, and additional bands at $1163 \mathrm{~cm}^{-1}$ and $1103 \mathrm{~cm}^{-1}$ reflecting the sulfone functionality. Molecular weights and polydispersity indices (PDI, Mw/Mn) of these polymers were measured by GPC in DMF against PMMA standards (Table 1). In the samples used for GPC in Figure 4 (plotting retention time vs. refractive index intensity), polymer 10 had an estimated $\mathrm{Mn}$ of 48,100 g/mole, and polymer 9 34,000 g/mole, with respective PDI values of 2.6 and 1.9 that are typical outcomes of step growth polymerizations.

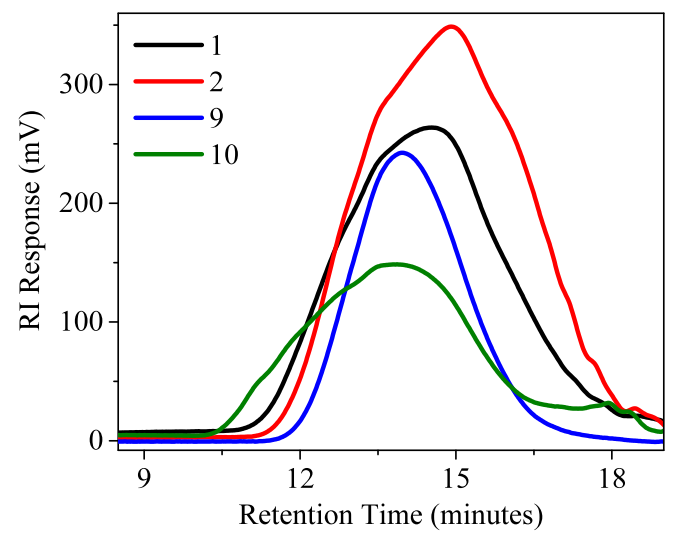

Figure 4. Overlaid GPC traces of polymers 1, 2, 9, and $\mathbf{1 0}$ (y-axis is the refractive index (RI) response).

Thermal characterization and heat release measurements. All of the synthesized polymers exhibit glass transition temperature (Tg) indicative of an amorphous or glassy morphology. The presence of deoxybenzoin reduced the $\mathrm{Tg}$ relative to a commercially available poly(aryl ether) $\left(220^{\circ} \mathrm{C}\right)$ [43]: for example copolymers 9 and $\mathbf{1 0}$ had $\mathrm{Tg}$ values of 200 and $172{ }^{\circ} \mathrm{C}$ respectively, whereas polymers 1 and 2 showed Tg values of 173 and $150{ }^{\circ} \mathrm{C}$ (Table 1). These deoxybenzoincontaining polymers exhibit significant thermal stability, with decomposition temperatures in the $375-470{ }^{\circ} \mathrm{C}$ range at $5 \%$ weight loss. The presence of deoxybenzoin in the polymer backbone impacts decomposition onset, $\mathrm{T}_{\mathrm{d}}$, as shown in Figure 5. Char yields at $800{ }^{\circ} \mathrm{C}$, revealed by TGA measurements, for deoxybenzoin-containing polysulfone 1 and polysulfoxide 2 were $42 \%$ and $54 \%$, respectively, whereas char yields of the polysulfone copolymer 9 and polysulfone-sulfide copolymer 10 were $46 \%$ and $43 \%$ respectively. 




Figure 5. TGA analysis (weight loss versus temperature) of polymers 1, 2, 9, and $\mathbf{1 0}$ under $\mathrm{N}_{2(\mathrm{~g})}$ atmosphere.

Thermal characterization of these sulfur-containing deoxybenzoin polymers revealed exceptionally low heat release capacity $(\mathrm{HRC})$ values of $<70 \mathrm{~J} \mathrm{~g}^{-1} \mathrm{~K}^{-1}$, and a total heat release (THR) of $<7 \mathrm{k} \mathrm{Jg}^{-1}$. This data, obtained by pyrolysis combustion flow calorimerty (PCFC), an oxygen consumption technique, places these novel deoxybenzoin containing polymers in the ultra-low flammability category, despite the absence of halogen in the structure.

Table 1. Data obtained for deoxybenzoin-containing polymers and copolymers with 4,4'-biphenol and 4,4'thiodiphenol.

\begin{tabular}{ccccccccc}
\hline Polymer & $\mathbf{m}$ & $\mathbf{n}$ & $\mathbf{X}$ & $\begin{array}{c}\mathbf{T}_{\mathbf{g}}{ }^{\mathbf{a}} \\
\left({ }^{\mathbf{C}} \mathbf{C}\right)\end{array}$ & $\begin{array}{c}\mathbf{T}_{\mathbf{d}}^{\mathbf{b}} \\
\left({ }^{\circ} \mathbf{C}\right)\end{array}$ & $\begin{array}{c}\mathbf{M}_{\mathbf{n}}{ }^{\mathbf{c}} \\
(\mathbf{g} / \mathbf{m o l e})\end{array}$ & $\begin{array}{c}\mathbf{M}_{\mathbf{w}}{ }^{\mathbf{c}} \\
(\mathbf{g} / \mathbf{m o l e})\end{array}$ & $\mathbf{P D I}^{\mathbf{c}}$ \\
\hline $\mathbf{1}$ & 0 & 1 & $\mathrm{SO}_{2}$ & 173 & 452 & 18400 & 57000 & 3.1 \\
$\mathbf{2}$ & 0 & 1 & $\mathrm{SO}$ & 150 & 375 & 13400 & 43500 & 3.2 \\
$\mathbf{9}$ & 0.5 & 0.5 & $\mathrm{SO}_{2}$ & 200 & 439 & 34000 & 64000 & 1.9 \\
$\mathbf{1 0}$ & 0.5 & 0.5 & $\mathrm{SO}_{2}$ & 172 & 468 & 48100 & 128000 & 2.6
\end{tabular}

\footnotetext{
${ }^{\mathrm{a}}$ Obtained by DSC in $\mathrm{N}_{2}$ at a heating rate of $10^{\circ} \mathrm{C} / \mathrm{min} .{ }^{b}$ measured by TGA in $\mathrm{N}_{2}$ at a heating rate of $20^{\circ} \mathrm{C} / \mathrm{min}$; $\mathrm{T}_{\mathrm{d}}$ $=5 \%$ weight loss temperature in $\mathrm{N}_{2}$, ${ }^{\mathrm{c}}$ Determined by GPC in DMF at $1.0 \mathrm{~mL} / \mathrm{min}$ at $50{ }^{\circ} \mathrm{C}$ calibrated with PMMA standards.
} 
Similarly constructive data was obtained in PCFC analysis: polymer 2, having a char yield of $54 \%$, exhibited HRC of $66 \mathrm{~J} / \mathrm{g}-\mathrm{K}$ and THR of $6.5 \mathrm{~K} \mathrm{~J} / \mathrm{g}$, a significant reduction relative to the commercially available homopolymer (polymer $9(\mathrm{~m}=0)$ has HRC of $228 \mathrm{~J} / \mathrm{g}-\mathrm{K}$ and THR of $13.5 \mathrm{~K} \mathrm{~J} / \mathrm{g}$ (Table 2). [44] Pyrolysis combustion flow calorimetry (PCFC) revealed that the HRC and THR values of the new polymers prepared decreased significantly with increasing incorporation of deoxybenzoin moieties (defining $\mathrm{HRC}$ as the maximum heat released divided by the heating rate). Describing these systems in terms of HRC eliminates reliance on heating rate that is typical of standard flammability measurements, rendering HRC a characteristic material property.[27-28]. THR is the total heat of complete combustion of the pyrolysis products per initial mass of the sample. Low HRC and THR values are thus useful indicators of flame retardancy, and predict non-flammable behavior in larger scale tests.[29] MCC characterization of the aromatic deoxybenzoin polysulfones $\mathbf{1}$ and polysulfoxides $\mathbf{2}$ revealed HRC values of 120 $\mathrm{Jg}^{-1} \mathrm{~K}^{-1}$ and $66 \mathrm{Jg}^{-1} \mathrm{~K}^{-1}$, and THR values of $10 \mathrm{kJg}^{-1}$ and $6.5 \mathrm{kJg}^{-1}$, respectively, while polysulfone copolymer 9 containing deoxybenzoin as a comonomer with equal molar amounts of 4,4'biphenyl exhibited HRC of $86 \mathrm{Jg}^{-1} \mathrm{~K}^{-1}$ and THR of $8 \mathrm{kJg}^{-1}$. (Figure 6) Thus, introduction of deoxybenzoin into a polyphenylsulfone backbone leads to the substantial HRC reduction (Table 2) relative to a commercial polyphenylsulfone, [44] and opens opportunities for the potential use of these polymers in materials applications that benefit from low flammability plastics. 


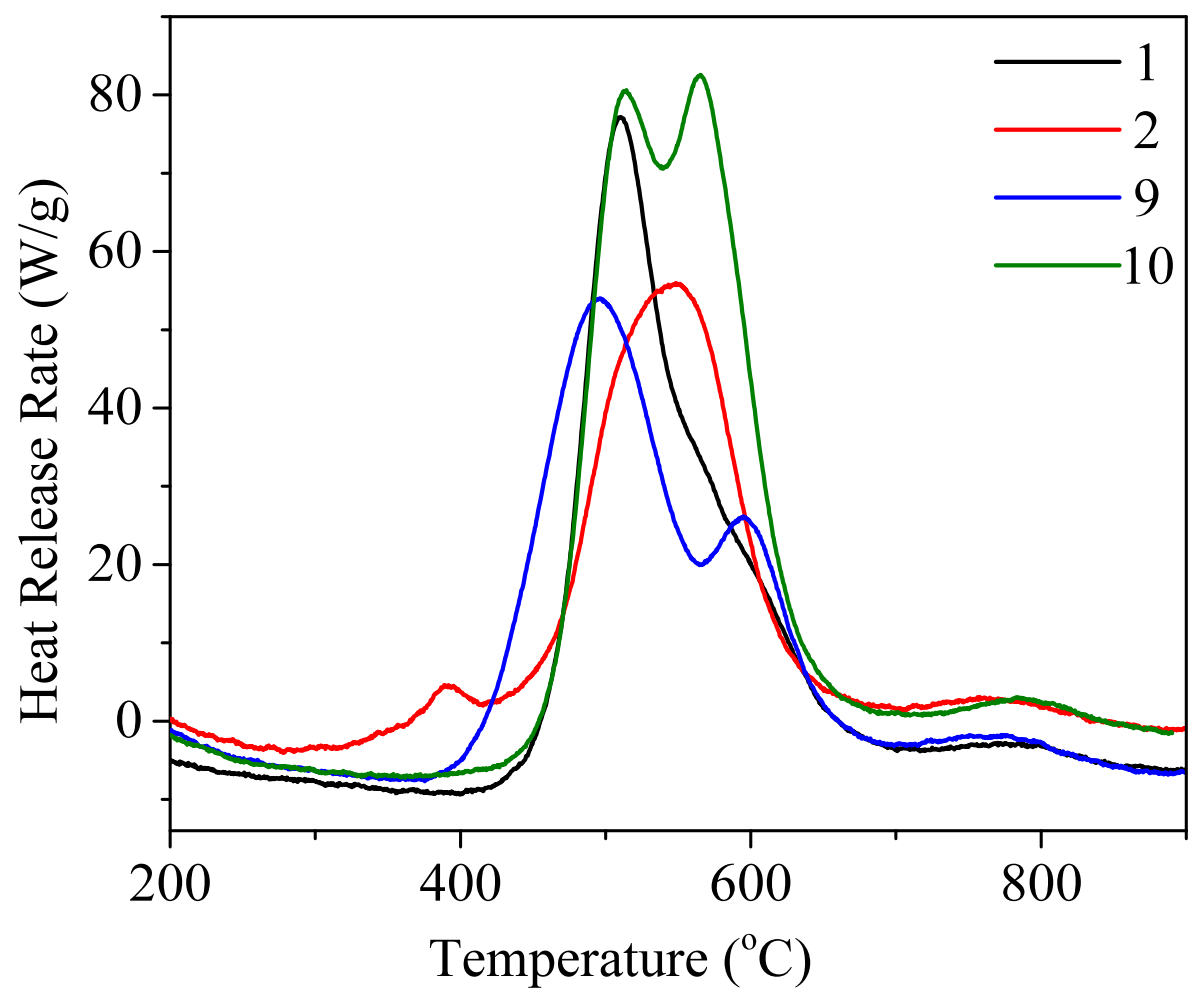

Figure 6. Heat release rate (HRR) verses temperature for polymers 1, 2, 9 and 10.

Table 2: Heat release capacity (HRC), total heat release (THR), and charring properties of deoxybenzoin-containing polymers and commercial polyether sulfone.

\begin{tabular}{cccccccc}
\hline Entry & Polymer & $\mathbf{m}$ & $\mathbf{n}$ & $\mathbf{X}$ & $\begin{array}{c}\text { HRC } \\
{\left[\mathbf{J ~ g}^{-\mathbf{1}} \mathbf{K}^{-\mathbf{1}}\right]}\end{array}$ & $\begin{array}{c}\text { THR } \\
{\left[\mathbf{K J ~ g}^{-\mathbf{1}}\right]}\end{array}$ & $\begin{array}{c}\mathbf{C h a r} \\
{[\mathbf{\%}]^{\mathbf{a}}}\end{array}$ \\
\hline 1 & BHDB-sulfone (1) & 0 & 1 & $\mathrm{SO}_{2}$ & 120 & 10 & 42 \\
2 & BHDB-sulfoxide (2) & 0 & 1 & $\mathrm{SO}$ & 66 & 6.5 & 54 \\
3 & BHDB/biphenyl (9) & 0.5 & 0.5 & $\mathrm{SO}_{2}$ & 86 & 8 & 46 \\
4 & BHDB/sufide (10) & 0.5 & 0.5 & $\mathrm{SO}_{2}$ & 138.5 & 10.7 & 43 \\
5 & Poly (aryl ether) (9) & 0 & 1 & $\mathrm{SO}_{2}$ & $228^{\mathrm{b}}$ & $13.5^{\mathrm{b}}$ & $\mathrm{c}$ \\
\hline
\end{tabular}

${ }^{a}$ Obtained from TGA at $800{ }^{\circ} \mathrm{C}$ in nitrogen (heating rate $20{ }^{\circ} \mathrm{C} \min ^{-1}$ ), ${ }^{b}$ Data obtained from reference $44 .{ }^{c}$ Not determined.

In summary, we described the integration of deoxybenzoin-based monomers into sulfurcontaining polymers, affording novel poly(aryl ether deoxybenzoin) sulfones, sulfoxides and sulfide polymers having low heat release properties and amenability to solution processing. 
Integration of deoxybenzoin units as comonomers considerably reduces the heat release capacity values of commercial aromatic polysulfones and other engineering thermoplastics, and further studies detailing the use of these new polymers in blends, and their resultant mechanical properties, will be reported subsequently.

Acknowledgements. The authors acknowledge with thanks financial support of this research from BASF, Inc through the BASF-NORA alliance, as well as the Federal Aviation Administration (FAA award \#14-G-012) and the facilities of the UMass Amherst Materials Research Science and Engineering Center on Polymers at UMass Amherst (NSF DMR-0820506).

\section{Notes and references}

[1] B. Gomara, L. Herrero, J. J. Ramos, J. R. Mateo, M. A. Fernandez, J. F. Garcia and M. Gonzaalez, J. Environ Sci Technol., 2007, 41, 6961.

[2] D. Smock, How advanced plastics saved lives on Asiana Flight 214, Plastics Today, 2013, July 9 th.

[3] Y. S. Kim, R. Davis, A. A. Cain, and J. C. Grunlan, Polymer, 2011, 52, 2847-2855.

[4] V. Benin, S. Durganala and A. B. Morgan, J. Mater. Chem., 2012, 22, 1180.

[5] S. L. Y-CM, Y. H. Yang, A. B. Morgan and J. C. Grunlan Advanced Materials, 2011, 23, 3926-31.

[6] A. B. Morgan, S. P. Putthanarat, Polym. Degrad. Stability 2011, 96, 23-32.

[7] J. He, G. Cai and C. A. Wilkie, Polym. Adv. Tech., 2014, 25, 160-167.

[8] (a) M. Zammarano, R. Kramer, R. Harris, J. Thomas, J. R. Shields, S. S. Rahatekar, S. Lacerda and J. W. Gilman, Polym. Adv. Technol., 2008, 19, 588- 595. (b) J. W. Gilman, C. L. Jackson, A. B. Morgan and H. Richard, Chem. Mater., 2000, 12, 1866-1873.

[9] J. W. Gilman and T. Kashiwagi, Nanocomposites: A revolutionary new flame retardant approach. SAMPE J. 1997, 33, 40-46. 
[10] J. W. Gilman, C. L. Jackson, A. B. Morgan and H. Richard, Chem. Mater., 2000, 12, 1866-1873.

[11] K. K. Shen, Boran-based flame retardants and fire retardancy, in C. A. Wilkie and A. B. Morgan, eds., Fire Retardancy of polymeric Materials- Taylor and Francis, 2nd Edn; 2010, ch. 9, pp. 207-237.

[12] K. K. Shen and E. Olson, Fire and Polymers IV-ACS symposium Series 992, American Chemical Society: Washington, DC, 2005, 224.

[13] K. K. Shen, S. Kochesfahani and F. Jouffret, Polym. Adv. Technology, 2008, 19, 469-

474.

[14] P. R. Horley and W. M. Worthington, US Patent 7638572, 2009.

[15] Q. Wu, C. Zhang, R. Liang and B. Wang, Carbon, 2008, 46, 1159-1174.

[16] J. Zhuge, Y. Tang, J. Gou, R. H. Chen, C. Ibeh and Y. Hu, Polym. Adv. Technol., 2011, 22, 2250-2256.

[17] J. Zhuge, J. Gou and R. H. Chen, J. App. Polym. Sci., 2012, 124, 37-48.

[18] J. Zhuge, J. Gou and C. Ibeh, Fire and Materials, 2012, 36, 241-253.

[19] C. C. Knight, C. Zeng, C. Zhang and B. Wang, Fire Mater., 2013, 97, 91-99.

[20] P. Bertrand, A. Jonas, A. Lashchewsky and R. Legras, Macromol. Rapid. Commun., 2000, 21, 319-348.

[21] T. Ranganathan, P. Cossette and T. Emrick, J. Mater. Chem., 2010, 20, 3681, 3687.

[22] K. A. Ellzey, T. Ranganathan, J. Zilberman, E. B. Couglin, R. J. Farris and T. Emrick, Marcomolecules, 2006, 39, 3553-3558.

[23] B-Y. Ryu, S. Moon, I. Kosif, T. Ranganathan, R. J. Farris and T. Emrick, Polymer, 2009, 50, 767-774. 
[24] V. Waals, A. J. H. Klunder, R. R. Van Buren and B. Zwanenburg, J. Mol. Catal., A 1998, 134, 179-89.

[25] M. L. Ramirez, DOT/FAA/AR-00/42. Springfield, VA, Department of Transportation, Federal Aviation Administration, National Technical Information, Service, 2001.

[26] T. Emrick and R. E. Lyon, Polym. Adv. Technol., 2008, 19, 609-19.

[27] R. N. Walters and R. E. Lyon, J. Appl. Polym. Sci., 2003, 87, 548-563.

[28] R. N. Walters and R. E. Lyon, J. Anal. Appl. Pyrolysis, 2004. 71, 27-46.

[29] A. B. Morgan and M. Bundy, Fire Mater., 2007, 31, 257-283.

[30] M. W. Szyndler, J. C. Timmons, Y. H. Zhan, A. J. Lesser, and T. Emrick, Polymer, 2014, $55,4441-4446$.

[31] T. Ranganathan, J. Zilberman, R. J. Farris, E. B. Couglin and T. Emrick, Macromolecules, 2006, 39, 5974-5975.

[32] T. Ranganathan, J. Zilberman, R. J. Farris, E. B. Couglin and T. Emrick, J. Polym. Sci., Part A: Polym. Chem. 2007, 45, 4573-80.

[33] J. S. Jurs and J. M. Tour, Polymer, 2003, 44, 3709-3714.

[34] P. M. Hergenrother, High Performance Polymers, 2003, 15, 3-45.

[35] Protecting America's Families from Toxic Chemicals Act of 2014, S. $2656 \quad$ (113th).

[36] Certain Polybrominated Diphenylethers; Significant New Use Rule, 71 Fed. Reg. 34,015 (Jun.13, 2006).

[37] A. B. Morgan, and C. A. Wilkie, Non-Halogenated Flame Retardant Handbook, Scrivener Publishing Wiley, 2014, ch. 1, pp. 1-16.

[38] B-Y. Ryu and T. Emrick, Macromolecules, 2011, 44, 5693-5700.

[39] R. E. Lyon, and R. N. Walters, J Anal. Appl. Pyrol., 2004; 71(1), 27-46. 
[40] ASTM Standard test method for determining flammability characteristics of plastics and other solid materials using microscale combustion calorimetry. $\quad$ ASTM D7309-13. West Conshohocken, PA: ASTM International; 2013. p.11.

[41] R. N Johnson, A. G Farnham, R. A Clendinning, W. F. Hale and C. N. Merriam. J Polym. Sci, Polym Chem Ed, 1967; 5(9), 2375-98.

[42] D. M. Knauss and J. B. Edson, Polymer 47, 2006, 3996-4003.

[43] Radel R-5000 is manufactured by Solvay Specialty Polymers and Ultrason is manufactured by BASF.

[44] R. E. Lyon and T. Emrick, Polym. Adv. Technol., 2008, 19, 609-619. 